\title{
Towards a Comprehensive Psychobiological Model of Major Depressive Disorder
}

\author{
Bernhard J. Mitterauer \\ Volitronics Institute for Basic Research, University of Salzburg, Salzburg, Austria \\ Email:mitterauer.b@gmail.com
}

How to cite this paper: Mitterauer, B. J. (2018). Towards a Comprehensive Psychobiological Model of Major Depressive Disorder. Open Journal of Depression, 7, 31-49. https://doi.org/10.4236/ojd.2018.72003

Received: February 1, 2018

Accepted: May 27, 2018

Published: May 30, 2018

Copyright $\odot 2018$ by author and Scientific Research Publishing Inc. This work is licensed under the Creative Commons Attribution International License (CC BY 4.0).

http://creativecommons.org/licenses/by/4.0/

\begin{abstract}
A psychobiological model of the etiopathology of major depression is proposed. It is hypothesized that a hyperintentional personality structure, if faced with non-feasible intentional programs in the environment, suffers from inner and outer stress. This stress situation leads to an excess of astrocytic receptors in glial-neuronal synaptic units, called tripartite synapses, and an overexpression of gap junctions in astroglial networks. The imbalance of synaptic information processing caused by the excess of astrocytic receptors leads to a protracted information processing which affects the behavior generating systems in the reticular formation in the brainstem. Since the activation of these systems is delayed, they cannot decide in real time which mode of behavior (e.g. eating, working, communicating, etc.) is appropriate to a specific sensory information from the environment. The modes of behavior comprise all psychobiological action patterns occurring in circadian time periods. A delay of synaptic activation of the systems in the brainstem reticular formation may lead to a displacement of the modes of behavior in the sense of a persistence of some modes ("must do") and the inability to produce others ("cannot do"). Such a severe behavioral disorder also affects the self-understanding of the patient resulting in a depressive mood. The mechanism of the displacement of the modes of behavior is shown in a computer simulation. Preliminary clinical data may support the model proposed and is briefly discussed.
\end{abstract}

\section{Keywords}

Major Depression, Pathophysiology, Glial-Neuronal Interaction,

Hyperintentionality, Behavioral Disorder

\section{Introduction and Hypothetical Model}

Depression is a serious, recurring and chronic disorder that afflicts up to $20 \%$ of 
the global population (Wang et al., 2017). Major depression has become the second leading contributor to the global disability burden by 2010 (Ferrari et al., 2010). The basic symptoms are depressed mood and loss of interest or pleasure (American Psychiatric Association, 2013). Clinical relevant neurobiological hypotheses of major depressive disorder comprise genetics, stress, chronobiology, neurochemistry (neurotransmitters, receptors etc.), and immunoendocrinology. However, we lack a thorough understanding of the etiopathophysiology of major depression (Hasler, 2010). Although most hypotheses are "neurocentric", there is growing evidence that the glial cell system, especially astrocytes, play a significant role in the pathophysiology of depression (Verkhratsky et al., 2014; Dallerac \& Rouach, 2016).

The brain consists of a double cell structure, the neuronal cell system and the glial cell system. It is experimentally well established that glia exert a modulatory function in their interactions with neurons (Araque et al., 2014). Glial-neuronal synaptic units, called tripartite synapses, are composed of the neural component (pre- and post synapse) and the astrocyte as the glial component. The interactions occur via transmitter substances, transporters, second messengers, ions etc. Extracellular receptors also operate in astrocyte-synapse interactions. Astrocytes build networks within and between astrocytes that embody non-overlapping domains (Oberheim et al., 2009). Gap junctions in the astroglial network consist of connexin proteins which function as conducting channels (Ransom \& Giaume, 2013).

My patho-psycho-physiological model of depressive behavior and depressive mood can be described as an elementary cycle (Figure 1). Perfectionistic personalities with high aspirations (Bibring, 1953) have a genetically epigenetically and educationally determined hyperintentional personality structure (Wang et al., 2017). If intentional programs are non-feasible in the environment (Ferrari et al., 2010), an inner and outer stress arises (American Psychiatric Association, 2013). Based on a genetic inclination to depression, stress may cause imbalances of information processing in tripartite synapses. I hypothesize that receptors on the astrocytic membrane and gap junctions in the astroglial network are overexpressed so that the neurotransmitter substances cannot occupy the excess of astrocytic receptors in real time causing a protracted synaptic information processing (Hasler, 2010). On the behavioral level, the normal frequency of the modes of behavior such as eating, sleeping, working, communicating etc. generated in the brainstem reticular formation, is displaced caused by protracted synaptic activation (Verkhratsky et al., 2014). Dependent on the time period of protracted synaptic information processing, some modes of behavior are not activated and others persist (Mitterauer, 2009). The patient cannot self-explain why he (she) is suffering from both "I cannot do" and "I must do". Such subjective feeling of impotence becomes a bothersome daily experience which leads to a loss of self understanding (Dallerac \& Rouach, 2016). The loss of self-understanding feeds negatively back to the hyperintentional personality structure. This 


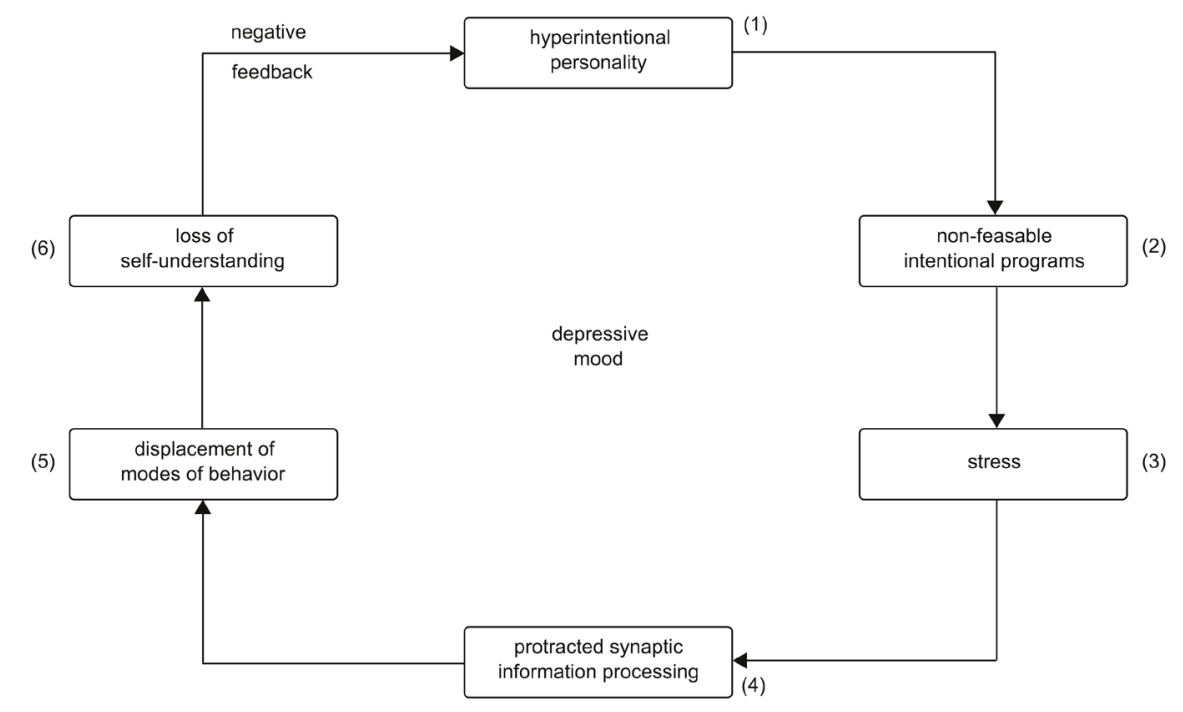

Figure 1. Elementary patho-psycho-biological cycle of major depression.

elementary patho-psycho-physiological cycle may generate a depressive mood.

The perspective of depression is organized as follows: First, I will present the typical hyperintentional personalityinclined todepression, and its inability to realize intentional programs in the environment. The essential biological picture focuses on protracted information processing in tripartite synapses caused by an excess of astrocytic receptors. Furthermore, in a computer simulation of the brainstem reticular formation (RF) is shown that the generation of the modes of behavior is displaced by delayed synaptic activation of the RF. After the discussion of testing, the hypothetical model preliminary clinical data are reported and briefly discussed.

\section{Hyperintentional Personality Structure}

Deep clinical interviews with patients suffering from major depression led to the concept of hyperintentional personality structure as a main psychological factor of inclination to depression (Mitterauer, 2009). Intentionality is defined as follows: an intentional program generates a specific multirelational structure in the inner and outer environment based on the principle of that program (Mitterauer, 2007). Hyperintentionality is given, if an intentional program persists, despite it being non-feasible in the environment. Bibring (1953) speaks of high aspirations of persons susceptible to depression.

It is often observed that parents of children susceptible to depression are convinced of having a genius daughter or son who will do "great things" and innovations in the future. Considering the life of genius artists and scientists they are suddenly incapable of working without a conceivable reason. For example, a great computer scientist saw a novel computer system "before his eyes", but he was incapable of communicating it for technical implementation. The typical personality structure susceptible to depression may be basically determined by an epigenetic process and education. In an epigenetic process certain genes are 
expressed in parent-origin-specific manner. Behavioral epigenetics attempts to provide a framework for understanding how the expression of genes is influenced by experience and environment (Champagne \& Mashoodt, 2012) in producing individual differences in behavior (Zhang \& Meaney, 2010), personality (Bagot \& Meaney, 2010), and mental disorders (Stuffrein-Roberts et al., 2008) or depression (Dalton et al., 2014).

Importantly, Freud (1917) characterized depression as a narcissistic neurosis. Since then, the concept of narcissism has been introduced in psychology and psychopathology describing absolute egocentric personalities. However, the original meaning of narcissism in the poem of Ovid (Ovidius Naso, 1983) is not only absolute self-reference or egocentricity, but basically non-feasible intentionality. The beautiful boy Narcissus strives to meet and touch his double, but he fails to grasp his mirror image in a pond and deceases. Whereas perfectionistic and egocentric persons often succeed, a hyperintentional person fails in realizing its intentions and may become depressed.

\section{Non-Feasibility of Intentional Programs and Stress}

Persons inclined to depression increasingly feel an inner pressure being unable to realize what they intend. Normally, in everyday life some intentions or plans are not realizable, but we can cope with these situations. Even in the case of burdensome life events, subjects can be resilient. Importantly, if a person is vulnerable to depression, negative life events are basically experienced as inappropriate to his or her intentions. If the intentional programs cannot be modified or adapted for coping with the environmental situation, a hyperintentional psycho-biological state arises and persists.

Depression research mainly focuses on environmental stressors and traumatic events in the pathogenesis of depression (Hasler, 2010; Baum \& Polsusnzy, 1999). Animal models of stress elucidate mechanisms that may contribute to the pathophysiology of depression such as disruption of neuroplasticity (Pittenger \& Duman, 2008), inflammation and long-term depressive-like phenotypes (Chu et al., 2016). Although environmental stressors can trigger a depressive state, an inner stress may basically be generated by the patient him (her) self, because of the non-feasibility of intentional programs. This inner stress may protract information processing in tripartite synapses caused by an overexpression of astrocytic receptors and gap junctions in the astroglial network (Mitterauer, 2009).

\section{Protracted Information Processing in Tripartite Synapse}

\subsection{Outline of a Tripartite Synapse and the Astroglial Network}

Experimental findings clearly indicate that signaling between neurons and astrocytes runs bidirectionally (Arague \& Navarrete, 2010; DePitta et al., 2013). Astrocytes can be stimulated by synaptic activity through activation of neurotransmitter receptors on astrocytes elevating $\mathrm{Ca}^{2+}$ concentrations that stimulate the release of neuroactive substances, called gliotransmitters (GT) (e.g. gluta- 
mate, adenosine-tri-phosphate, D-serine). GTs modulate synaptic excitability and synaptic transmission (Perea et al., 2009). These synapse-astrocyte communications led to the novel concept of the tripartite synapse (Arague et al., 1999).

Figure 2 outlines a model of glutamatergic tripartite synapse. The excitatory neurotransmitter glutamate (GLU) released from the presynapse (prs) activates cognate postsynaptic receptors (por), extrasynaptic receptors (esr), and astrocytic receptors (acr). GLU is uptaken by transporters ( $t$ ). The occupancy of acr by GLU elevates $\mathrm{Ca}^{2+}$ concentration which stimulates the production of GT. GT feeds back to cognate receptors on the psr. Since astrocytes express most of the receptors identified in neurons (Kettenmann \& Zorec, 2013), they are able to sense and respond to neuronal signals modulating synaptic transmission (Bradley \& Challiss, 2012).

The astroglial network is interconnected by gap junctions (GJ). GJ provide a structural link by which single cells are coupled to build a functional network with communication dynamics that cannot be exerted by individual cells. GJ in the glial network consist of connexins that form gap junction channels by hemichannels of different kinds (Ransom \& Giaume, 2013). Astrocytes are interconnected via GJs with their neighbors interacting with neurons mainly in tripartite synapses (Arague et al., 1999). Importantly, the number and composition of GJs can be dynamically regulated by upregulation of connexin biosynthesis or decreasing the rate of connexin degradation in the endoplasmic reticulum, and enhancing gap junction assembly. If GJs are frequently coupled within time scales of seconds or hours, they form plaques (Ransom \& Giaume, 2013). I hypothesized that the overexpression and underexpression of connexins does not only dysregulate the astroglial network, but may also influence the expression of astrocytic receptors (Mitterauer, 2011).

\subsection{Overexpression of Gap Junctions and Astrocytic Receptors}

Figure 3 depicts overexpressed gap junctions in the astroglial network and overexpressed astrocytic receptors in the tripartite synapses. This imbalance of astroglia functions may be basically responsible for depression. I hypothesize that the upregulation of connexins may cause an overexpression of astrocytic receptors which cannot be occupied by neurotransmitters in real time. This leads to an underproduction of gliotransmitters (GT) because $\mathrm{Ca}^{2+}$ concentration is diminished so that GTs negatively feedback to the cognate presynaptic receptors, and synaptic information processing is protracted.

Recently, Quesseveur, Portal, Basic et al. (2015) investigated the role of hippocampal astroglial connexin 43 in emotionality and the effects of selective serotonin reuptake inhibitors. The main result is the following: considering that phosphorylation is a prerequisite for acute function of connexins (Solan \& Lampe, 2009), the therapeutic effects of antidepressant drugs might implicate the functional inactivation of connexin 43. This finding may support my model of the pathophysiology of major depression, since it allows the interpretation that overexpressed connexins become reduced by antidepressant drugs balancing 


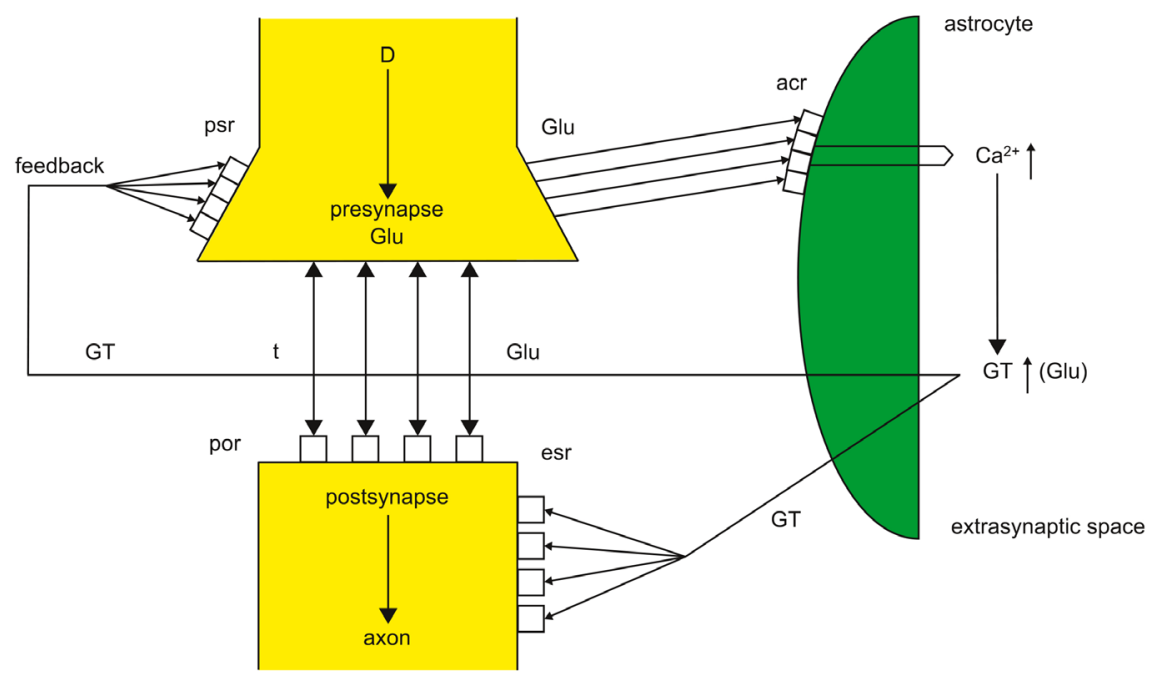

Figure 2. Schematic representation of a glutamatergic synapse. The excitatory neurotransmitter glutamate (GLU) is activated by a dendrite (D). GLU activates postsynaptic receptors (por) and is reuptaken on the presynapse via transporters (t). GLU also occupies receptors on the astrocyte activating channels that leads to an increase in calcium concentration and to the production of gliotransmitters (GT). The release of (GT) from the astrocyte occupies presynaptic receptors (psr), por and extrasynaptic receptors (esr) on the postsynapse. The effect of GLU corresponds with a feedback mechanism on the presynapse and the depolarization by the occupancies of por and esr (11).

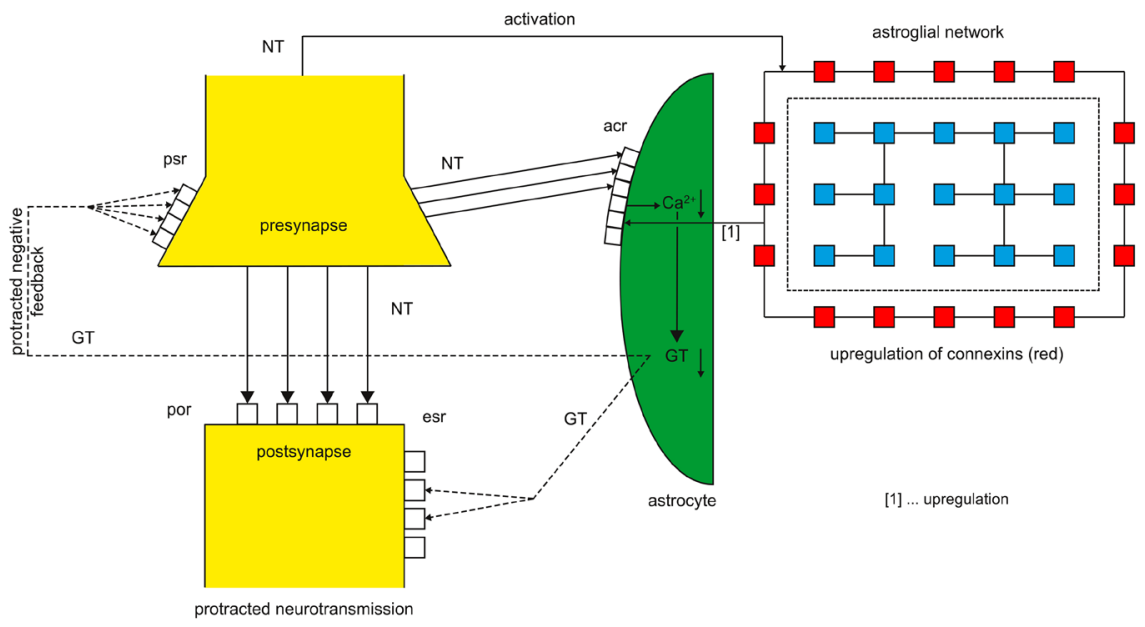

Figure 3. Upregulation of glial connexins or gap junctions and overexpression of astrocytic receptors cause protracted synaptic information processing responsible for the pathophysiology of depression. Neurotransmitters (NT) released from the presynapse activate postsynaptic receptors (por) and astrocytic receptors (acr). The upregulation of glial connexins forming gap junctions (GJs, red) upregulates the expression of acr. Overexpressed acr cannot completely be occupied by NT causing a diminished concentration of $\mathrm{Ca}^{2 \mathrm{t}}$ and a prolonged production of gliotransmitters (GT). (dashed lines). This leads to a protracted activation of psr, por and extrasynaptic receptors (esr) so that neurotransmission is delayed.

synaptic transmission. In addition, functional imaging studies of patients with depression indicate that the clinical response to antidepressants is different in 
the hippocampal and prefrontal area. Whereas antidepressant substances reduce functional activity in the hippocampus and the limbic regions, they increase functional activity in the prefrontal cortex (Mayberg et al., 2000). I hypothesize that in depression the overexpression of gap junctions and astrocytic receptors operate hyperintentionally in emotion processing regions such as in hippocampus. In contrast, in cognition processing areas as the prefrontal cortex, gap junctions and astrocytic receptors are underexpressed. In the later case, environmental information cannot be "grasped" in momentum so that the patient is irritated by information flooding.

Basically, most of the typical receptors for neurotransmission has been identified on the astrocytic membrane (Kettenmann \& Zorec, 2013). However, dysregulations of the expression of astrocytic receptors are as yet not elucidated in depression, but upregulations of astrocytic receptors are already found in Alzheimer's disease (Ishida et al., 2006) and in Parkinson's disease (Yu et al., 2012). Currently, the Fuxe Group investigates receptor-receptor coupling in tripartite synapses and found that abnormal receptor-receptor coupling in inflammation, possibly responsible for depression, dysregulates neurotransmission (Fuxe et al., 2014). This new approach to our understanding of the functions and dysfunctions of receptors in synapse-astrocyte interactions could elucidate the role of astrocytic receptors in depression.

Admittedly, the decrease and hypofunction of astrocytes seems to speak against the model proposed here. However, experimental findings depend on the stage or course of illness (Hasler, 2010). Importantly, there is some evidence that receptors on astrocytes are upregulated. In animal models of chronic stress adenosine $\mathrm{A}_{2 \mathrm{~A}}$ receptors are upregulated and polymorphisms of $\mathrm{A}_{2 \mathrm{~A}}$ receptors are associated with emotional disturbances and their over-expression triggers emotional dysfunction (Rial et al., 2015). This mechanism could also work in depression and should be elucidated in brains with depression.

\section{The Concept of the Modes of Behavior}

According to Iberall and McCulloch (1969), a living system like man is highly dynamic. In order to produce an integrated behavior, it must be capable of generating stable system states, called modes of behavior. Morphological and physiological investigations indicate that the reticular formation (RF) in the brainstem may function as an integrative matrix (Scheibel \& Scheibel, 1968; Hobson \& Scheibel, 1980) organized in modules, incorporating a large number of neurons receiving roughly the same input providing roughly the same output in their environments (Arbib, 2007). In addition, I proposed a new model of the RF referring not only to the neuronal system, but also to the glial cell system (Mitterauer, 2015). Although we do not normally think of human behavior as modal, most people may agree that their quality of consciousness is unitary and they can only do one thing well at a time (Kilmer et al., 1969). The essential modes of behavior as sleeping, eating, working, communicating etc. will have a time constant of the order of a female menstrual period. We have further elaborated the number of 
21 modes of behavior listed by the McCulloch group to 35 modes of behavior (Table 1). Although this list itself could be challenged, I will focus on the exploratory power for the scientific approach to depression research.

The RF operates by an abductive logic (Peirce, 1958; McCulloch, 1966; Josephson \& Josephson, 1995) that formalizes the selection process of the appropriate program requests. Figure 4 outlines a biocybernetic model of the generation of six modes of behavior in a time period $\left(t_{1}\right.$ to $\left.t_{6}\right)$. Each time period $\left(t_{1} \cdots t_{6}\right)$

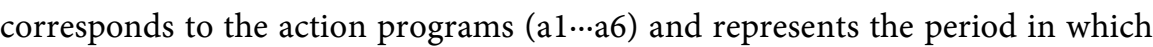
one of the six simulated modes of behavior is activated.

Environmental information from the perception systems is processed in specialized cortical and subcortical systems (Barbas \& Zikopoulos, 2007). For the sake of simplicity, it is only referred to the cognitive, emotional, psychomotor and autonomic-circadian systems. At the moment $t_{1} t_{0} t_{6}$ the decision systems in the RF decide based on abduction, which information quality (domain) is most appropriate to an action program $\left(\mathrm{a}_{1} \cdots \mathrm{a}_{6}\right)$. Examples of typical action programs are mental activity, anxious, euphoric, work, eat and sleep. Dependent on the action program activated, the integrative function of the RF is capable of commanding and controlling the generation of a pertinent mode of behavior such as mental activity, feeling of anxiety, euphoria or to work, eat and sleep.

In the perspective of the brain model here proposed a glial-neuronal compartment or unit of interaction corresponds to one specific program structure. These program structures are genetically determined, and the activity of the programs alters within different time scales. Therefore, the brain permanently operates in different system states that correspond not only genetically, but also in relation to the environment and to intentions (Mitterauer, 2015). Basically, the program structures or compartments may function as hypotheses that are tested in the environment. If conditions in the environment change, the multicompartmental modular organization must adapt the program structures. Decisively, if synaptic processing of environmental information is protracted, modes of behavior cannot be activated in real time. This may represent the core pathophysiological dysregulation in major depression.

\section{Displacement of the Modes of Behavior in Depression}

As already hypothesized, in depression an excess of astrocytic receptors in tripartite synapses may cause a severe delay of information processing leading to a displacement of the generation of the modes of behavior. In a computer simulation we are able to show how such a delay of synaptic information processing displaces the pattern of the modes of behavior. The computer system applied processes the information from the sensory systems or synapses and selects the appropriate pattern of modes of behavior according to the principle of redundancy of potential command.

\section{Simulation Example of a Hypersomnic Depression}

In our standard model of the implementation of the principle of redundancy of 
Table 1. SSBA (Salzburg subjective behavior analysis). Has the frequency of the following behaviors changed during the last two weeks in comparison to normal? If so, how frequently do you do or feel the following: Please give an example and explanation, if you choose NEVER or ALWAYS.

\begin{tabular}{|c|c|c|c|c|c|c|c|}
\hline No. & Behavior & Never & Less often & No change & $\begin{array}{l}\text { More } \\
\text { often }\end{array}$ & Always & $\begin{array}{c}\text { Explanation \& } \\
\text { example }\end{array}$ \\
\hline 1 & Sleep & & & & & & \\
\hline 2 & Vomit & & & & & & \\
\hline 3 & Feel alert \&focused & & & & & & \\
\hline 4 & Feel greedy & & & & & & \\
\hline 5 & Feel generous & & & & & & \\
\hline 6 & Eat & & & & & & \\
\hline 7 & Bowel urgency & & & & & & \\
\hline 8 & Move around & & & & & & \\
\hline 9 & $\begin{array}{c}\text { Feel stiff } \\
\text { (not able to move) }\end{array}$ & & & & & & \\
\hline 10 & Feel afraid & & & & & & \\
\hline 11 & Feel happy & & & & & & \\
\hline 12 & $\begin{array}{l}\text { Deal with problems, } \\
\text { situations, people }\end{array}$ & & & & & & \\
\hline 13 & Avoid People & & & & & & \\
\hline 14 & Perform sexual activity & & & & & & \\
\hline 15 & $\begin{array}{c}\text { Perform } \\
\text { mental/intellectual } \\
\text { activity }\end{array}$ & & & & & & \\
\hline 16 & Drink & & & & & & \\
\hline 17 & Urgetourinate & & & & & & \\
\hline 18 & Quarrel & & & & & & \\
\hline 19 & Feel peaceable & & & & & & \\
\hline 20 & Feel like fighting & & & & & & \\
\hline 21 & $\begin{array}{l}\text { Feel resigned and } \\
\text { non-resistant }\end{array}$ & & & & & & \\
\hline 22 & Feel jealous & & & & & & \\
\hline 23 & Feel indulgend & & & & & & \\
\hline 24 & Work & & & & & & \\
\hline 25 & Rest & & & & & & \\
\hline 26 & Talk & & & & & & \\
\hline 27 & Listen & & & & & & \\
\hline 28 & Feel pleased & & & & & & \\
\hline 29 & Feel annoyed/irritaded & & & & & & \\
\hline 30 & Laugh & & & & & & \\
\hline 31 & Cry & & & & & & \\
\hline 32 & $\begin{array}{c}\text { Communicate with } \\
\text { others }\end{array}$ & & & & & & \\
\hline 33 & Seclude yourself & & & & & & \\
\hline 34 & Feel cheerful & & & & & & \\
\hline 35 & Feelsad & & & & & & \\
\hline
\end{tabular}


$[1]$

[2]
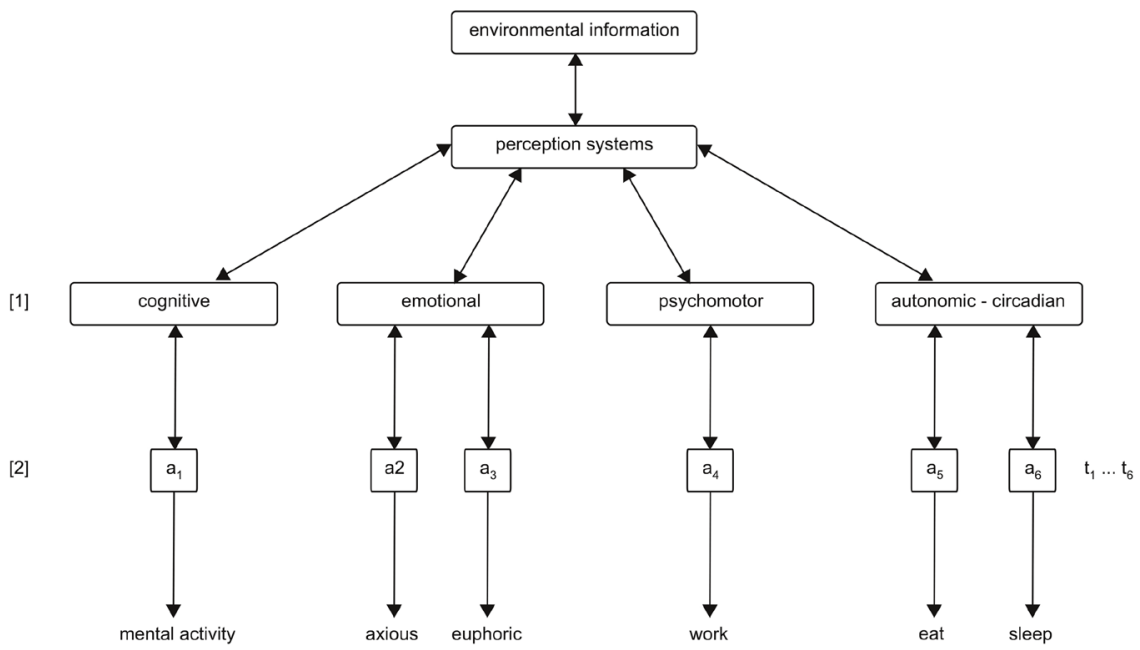

[1] ... Cortical and subcortical information processing

[2] ... Brainstem reticular formation

Figure 4. Biocybernetic model of generation of modes of behavior in the period $t_{1} \cdots t_{6}$. Perception systems process environmental information in cognitive, emotional, psychomotor and autonomic-circardian domains of the brain (cortical and subcortical). At the moments $t_{1} \cdots t_{0} t_{6}$ the reticular formation selects most appropriate information to an action program $\left(a_{1} \cdots a_{6}\right)$ as mental activity, anxious, euphoric, work, eat, sleep. (double headed arrows indicate feedback mechanisms).

potential command, all cellular and subcellular systems operate synchronously. This organization secures a real time information processing of the synaptic input from the sensory systems and also correct decision making in the RF based on incoming information. Figure 5 represents 61 steps of the simulation by selecting 5 modes of behavior. Take the behavior of a housewife in the late morning as an example, first she communicates $\left(\mathrm{N}_{3}\right)$, then she prepares a meal $\left(\mathrm{N}_{1}\right)$ and concentrates on an interesting radio report $\left(\mathrm{N}_{5}\right)$. After a short communication during a phone call $\left(\mathrm{N}_{3}\right)$, she continues her housework and again she concentrates on the radio report $\left(\mathrm{N}_{5}\right)$. The modes of sleeping and eating do not occur in the sense of a normal behavior period in the late morning.

Now, supposing a temporal delay of information processing in tripartite synapses in line with model proposed here, the system will continue to operate on the principle of redundancy of potential command, but in a modified manner. The point is that the update of the neuronal network in the RF operates at a higher frequency than the synapses of the sensory information processing systems. The intensity of the displacement of the modes of behavior may depend on the duration of phases in which synapses do not transfer information to the decision network in the RF. The behavior displacement shown in Figure 6 represents a proportion of one to two with concern to the neuronal updates in the networks of the brainstem and the synaptic updates of the perception systems. Here, a significant period of sleeping with less frequent change to other modes of behavior takes place. The housewife falls asleep already in the late morning. She is only able to eat and briefly communicate on the phone. Most 

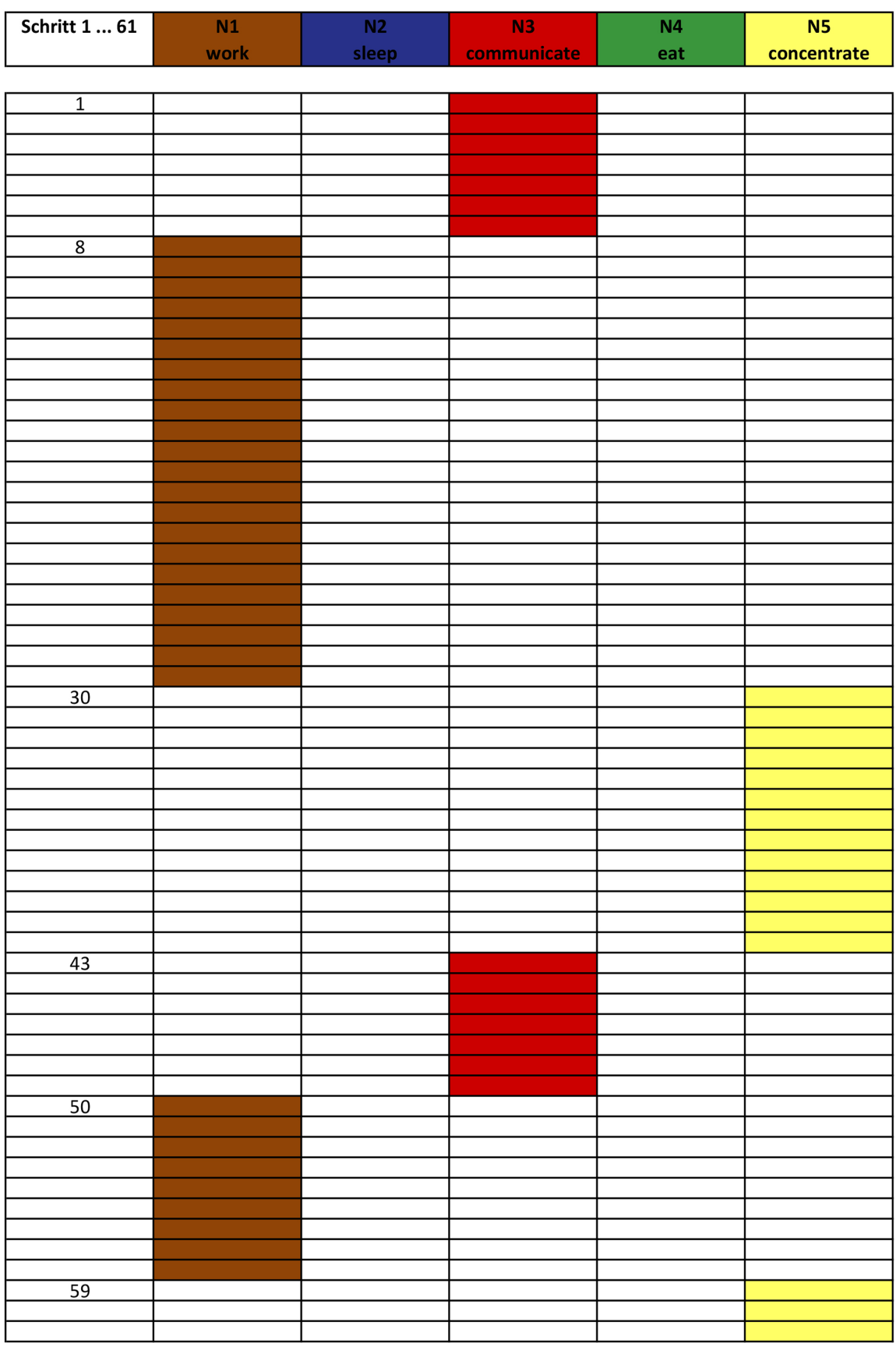

Figure 5. Simulation of the generation of five modes of behavior in the RF in undisturbed

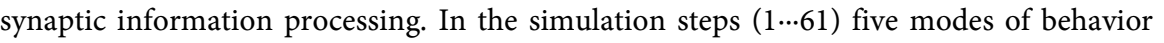
$\left(\mathrm{N}_{1} \cdots \mathrm{N}_{5}\right)$ are selected by the system. The system first selects communicating $\left(\mathrm{N}_{3}\right)$, then working $\left(\mathrm{N}_{1}\right)$, concentrating $\left(\mathrm{N}_{5}\right)$, communicating $\left(\mathrm{N}_{3}\right)$ working and concentrating $\left(\mathrm{N}_{5}\right)$. Note, to sleep $\left(\mathrm{N}_{2}\right)$ is not generated during this simulation period.

importantly, she is unable to keep up with her housework.

If the delay of synaptic information processing is further enhanced because of an excess of astrocytic receptors, the neuronal network in the RF needs more time (three time steps) to generate any mode of behavior at all. The generated mode of sleeping persists during the whole simulation period of 61 steps and 


\begin{tabular}{|c|c|c|c|c|c|}
\hline Schritt 1 ...61 & $\begin{array}{c}\text { N1 } \\
\text { work }\end{array}$ & $\begin{array}{c}\text { N2 } \\
\text { sleep }\end{array}$ & $\begin{array}{c}\text { N3 } \\
\text { communicate }\end{array}$ & $\begin{array}{c}\text { N4 } \\
\text { eat }\end{array}$ & $\begin{array}{c}\text { N5 } \\
\text { concentrate }\end{array}$ \\
\hline
\end{tabular}

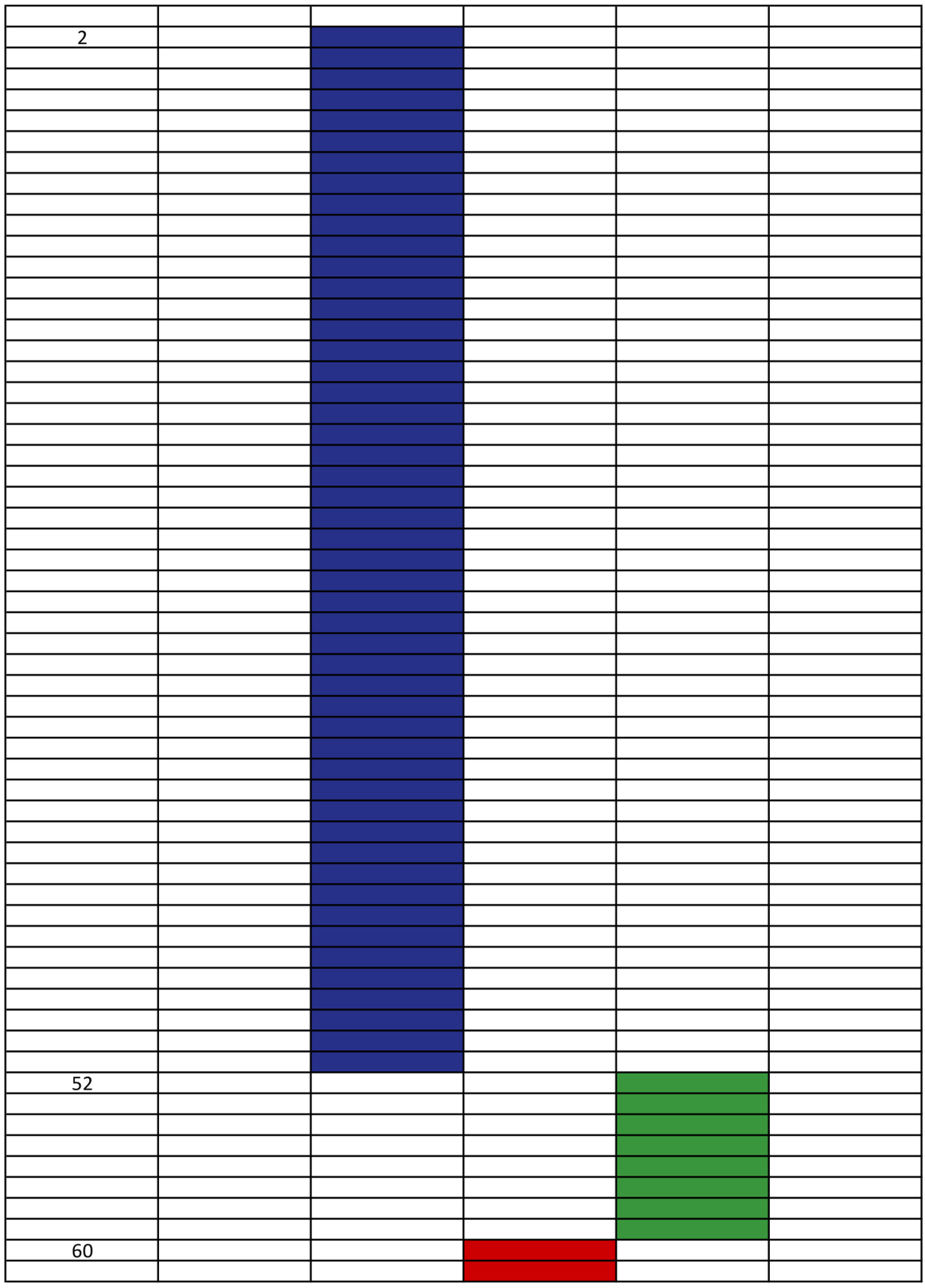

Figure 6. Displacement of the generation of the modes of behavior caused by delayed synaptic information processing. A delay of synaptic information processing causes a long sleeping period $\left(\mathrm{N}_{2}\right)$, and short eating $\left(\mathrm{N}_{4}\right)$ and communicating $\left(\mathrm{N}_{3}\right)$ periods. Working $\left(\mathrm{N}_{1}\right)$ and concentrating $\left(\mathrm{N}_{5}\right)$ are not selected.

does not change to any other mode of behavior (Figure 7). Such a severe disorder of the usual behavior pattern can be diagnosed as a hypersomnic depression. Depending on the degree of excess of astrocytic receptors in the tripartite synapses and the brain area affected, the severity of the depressive symptoms will vary accordingly. For instance, if the prefrontal cortex is predominantly affected, a cognitive impairment will dominate the depressive symptomatology. The same 


\begin{tabular}{|c|c|c|c|c|c|}
\hline Schritt 1 ...61 & $\begin{array}{c}\text { N1 } \\
\text { work }\end{array}$ & $\begin{array}{c}\text { N2 } \\
\text { sleep }\end{array}$ & $\begin{array}{c}\text { N3 } \\
\text { communicate }\end{array}$ & $\begin{array}{c}\text { N4 } \\
\text { eat }\end{array}$ & $\begin{array}{c}\text { N5 } \\
\text { concentrate }\end{array}$ \\
\hline
\end{tabular}
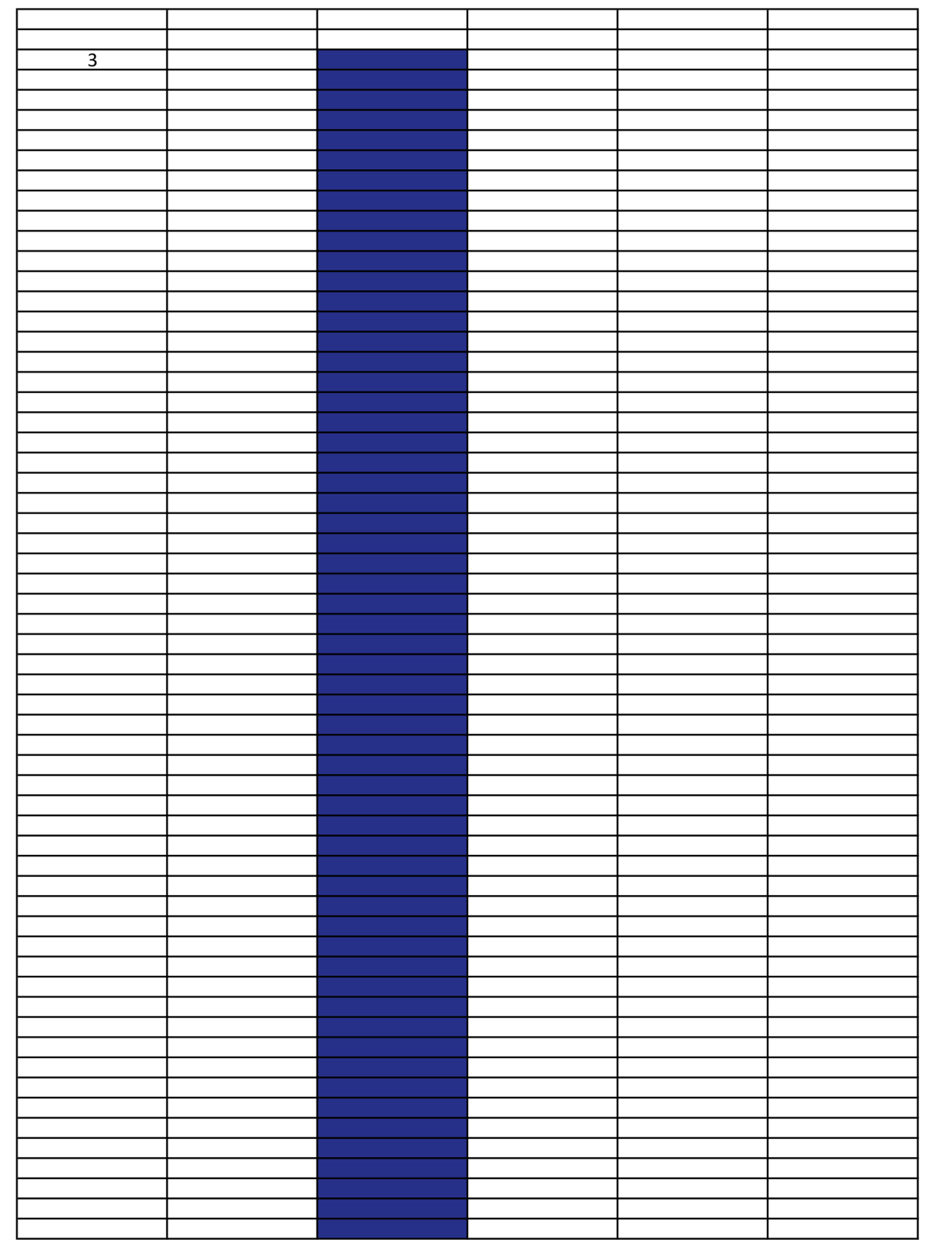

Figure 7. Persistence of one mode of behavior caused by a severe delay of synaptic information processing. Here, the synaptic information processing is further prolongated. The system requires three time steps for selecting one of the five modes of behavior at all. Note, the system only selects sleeping and does not change to another mode of behavior during the whole simulation period ( $1 \cdots 61)$.

holds for a prevailing delay of information processing in the limbic regions of the brain. The compulsive persistence of a mode of behavior is mostly not related to reality so that the capability to decide in real time which mode is appropriate to a given environmental information is at least temporarily lost. The patient cannot explain this severe behavioral disorder to himself, and loses his (her) self-understanding and a depressive mood is the consequence (Mitterauer, 2009). 


\section{Testing the Model}

Two major methodological breakthroughs enable a profound understanding of astrocytic activities in tripartite synapses: calcium imaging and advanced optical microscopy (Li et al., 2013). Genetically encoded calcium indicators allow more detailed analysis of astrocyte functions. In addition, two-photon microscopy enables the observation of fluorscence with superior penetration depth (Harada et al., 2016). Therefore, protracted information processing in tripartite synapses in emotion processing regions as the hippocampus could be identified in vivo. Although we do not know, if an animal is really in a state of major depression, protracted synaptic information processing might be observable, if e.g the animal is hungry and cannot find any food. In this case the animal is biologically urged to eat ("must do"), but this striving is unfeasible. Importantly, such experiments could elucidate, if protracted information processing in tripartite synapses is determined by an overexpression of astrocytic receptors.

What the investigation of the decision mechanisms in the RF concerns, biological experiments are faced with limitations, since the interactions of the RF with the systems of sensory information processing are highly complex and cannot fully be tested in living brains. Here, computer simulations of the model proposed may provide a basis for further clinical investigations.

Admittedly, a big challenge represents the testing of the effect of a hyperintentional personality structure or the pathophysiology of depression. Based on a questionnaire for the assessment of a hyperintentional personality structure, long-term programs using functional imaging methods and optogenetics could elucidate the role of hyperintentionality on protracted, synaptic information processing and the decay of neuronal and glial cells caused by chronic system stress. Since an animal with high aspirations is hardly imaginable, testing of the possible role of hyperintentionality in the etiopathophysiology of major depression, should exclusively be conducted on human brains.

\section{Preliminary Clinical Results}

Currently, we are working on the international project "Comprehensive psychobiological model of major depressive disorder". Preliminarily, a small sample of outpatients of the Psychiatric Clinic, PMU Salzburg, may support the model proposed. Thirty patients (18 female, 12 male) suffering from major depression (American Psychiatric Association, 2013) are investigated by a new questionnaire entitled "The Salzburg Subjective Behavioral Analysis (SSBA)" (Mitterauer, 2009). The SSBA consists of 35 items describing 35 different modes of behavior. We asked, if the frequency of the listed modes of behavior had changed during the last two weeks in comparison to normal, i.e. to a time of the patients well-being. Each question had a choice of five possible answers ranging from "no change", "less often", and "more often" to the extreme positions "never" and "always". Since the sample is not representative, statistical data are here omitted. 


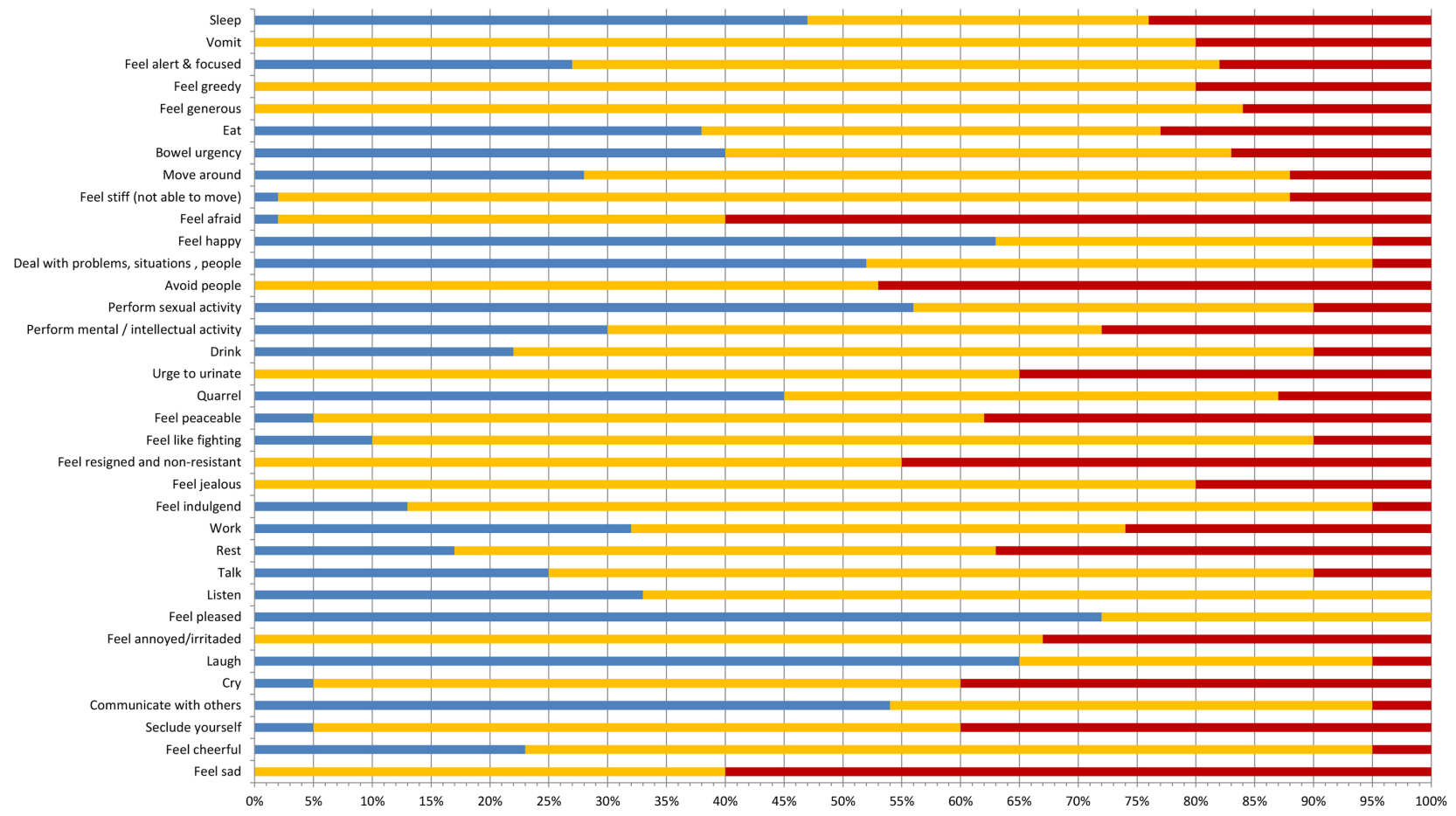

Figure 8. Behavioral analysis of 30 patients with major depression. The frequency of the extreme positions "cannot do" (blue) and "must do" (red) is listed. Unchanged/seldom/more often frequencies are shown in between (yellow).

Figure 8 represents the frequency of extreme positions of the sample $(n=30)$. This comprehensive behavioral analysis of the patients detected a severe displacement of the normal behavioral pattern that is usually not fully explored or not reported by the patient. Whereas persistent anxiety, hypersomnia, hyperphagia and polakisuria are included in various diagnostic instruments, we additionally explored "hyper- and hypomodes" to which diagnostic criteria of major depressive disorder do not refer. Extreme positions (hypermodes) concerned emotional, cognitive and psychobiological domains. Some hypermodes seem to be paradoxical to depression and usually represent symptoms of a bipolar state as for example the urge to smile, to communicate or to speak permanently (Akiskal \& Benazzi, 2008).

Other hypermodes as the urge to work (workaholics) (Nie \& Sun, 2016), the greed for objects (chocoholics, compulsive buying) (Smeets et al., 2009; Hague et al., 2016) or excessive internet use (Kuss \& Lopez-Fernandez, 2016) are commonly classified as symptoms of addictions, obsessive compulsive disorders orcomorbidities (Thaipisuttikul et al., 2014). In these cases an antidepressive medication provides a basis for successful psychotherapeutic strategies.

\section{Concluding Remarks}

The significance of the present perspective lies in presenting an elementary patho-psycho-biological model towards a comprehensive understanding of major depressive disorder. It focuses on a hyperintentional personality structure 
stressed by non-feasible intentional programs. Given a genetic inclination to depression, information processing in tripartite synapses is delayed caused by the overexpression of astrocytic receptors. Since synaptic information processing is protracted, the modes of behavior generated in the RF cannot be activated in real time. Dependent on the protraction time the pattern of the modes of behavior becomes increasingly displaced. One or more modes are not generated ("cannot do") and others persist ("must do"). The interplay of these mechanisms leads to the loss of self-understanding and depressed mood.

The model proposed here must be tested on representative samples of patients with depression. The reported preliminary clinical findings indicate for a broader understanding of depressive behavior. This especially concerns hypermodes ("must do") that are commonly classified as addictions or obsessive-compulsive disorders. Admittedly, the underlying brain model of tripartite synapses and the RF must be further elaborated on experimental results. In addition, computer simulations may elucidate the complex decision mechanisms in the RF (Humphries et al., 2006). Recent imaging methods could provide evidence, when and where the activation pattern switches, if an action selection of a mode of behavior occurs. Although behavioral analyses of patients suffering from depression can be conducted as a structured interview with the SSBA questionnaire, the search for biological parameters is necessary. Together, I suggest that this new psychobiological model of basic depressive disorder may represent a further step towards a comprehensive model of major depression and may contribute to our understanding of this global disability burden.

\section{Acknowledgements}

I am grateful to Peter Zinterhof, jr. for the computer simulations, Christian Streili for designing the figures and tables, and Marie Motil for preparing the final version of the paper.

\section{References}

Akiskal, H. S., \& Benazzi, F. (2008). Continuous Distribution of Atypical Depressive Symptoms between Major Depressive and Bipolar Iidisorders: Dose-Response Relationship with Bipolar Family History. Psychopathology, 41, 39-42. https://doi.org/10.1159/000109954

American Psychiatric Association (2013). Diagnostic and Statistical Manual of Mental Disorders (5th ed.). Washington DC.

Arague, A., \& Navarrete, M. (2010). Glial Cells in Neuronal Network Function. Philosophical Transactions of the Royal Society of London. Series B, 365, 2375-2381. https://doi.org/10.1098/rstb.2009.0313

Arague, A., Parpura, V., Sanzgiri, R.P. and Haydon, P.G. (1999). Tripartite Synapses: Glia, the Unacknowledged Partner. Trends in Neurosciences, 22, 208-215. https://doi.org/10.1016/S0166-2236(98)01349-6

Araque, A., Carmignoto, G., Haydon, P. G. et al. (2014). Gliotransmitters Travel in Time and Space. Neuron, 81, 728-739. https://doi.org/10.1016/j.neuron.2014.02.007 
Arbib, M. A. (2007). Modular Models of Brain Function. Scholarpedia, 2, 1869. https://doi.org/10.4249/Scholarpedia

Bagot, R. C., \& Meaney, M. J. (2010). Epigenetics and the Biological Basis of Gene $\times$ Environment Interactions. Journal of the American Academy of Child and Adolescent Psychiatry, 49, 752-771. https://doi.org/10.1016/j.jaac.2010.06.001

Barbas, H., \& Zikopoulos, B. (2007). The Prefrontal Cortex and Flexible Behavior. Neuroscientist, 13, 532-545. https://doi.org/10.1177/1073858407301369

Baum, A., \& Polsusnzy, D. (1999). Health Psychology: Mapping Biobehavioral Contributions to Health and Illness. Annual Review of Psychology, 50, 137-163. https://doi.org/10.1146/annurev.psych.50.1.137

Ben, H., Jo, H., \& Stephen, K. (2016). Treatments for Compulsive Buying: A Systematic Review of the Quality, Effectiveness and Progression of the Outcome Evidence. Journal of Behavioral Addictions, 5, 379-394. https://doi.org/10.1556/2006.5.2016.064

Bibring, E. (1953). The Mechanism of Depression. In P. Greenacre (Ed.), Affective Disorders (pp. 13-28). New York: International Universities Press.

Bradley, S. J., \& Challiss, J. (2012). G Protein-Coupled Receptor Signalling in Astrocytes in Health and Disease: A Focus on Metabotropic Glutamate Receptors. Biochemical Pharmacology, 84, 249-259. https://doi.org/10.1016/j.bcp.2012.04.009

Champagne, F.A., \& Mashoodt, R. (2012). Genes in Context: Gene-Environment Interplay and Origins of Individual Differences in Behavior. Current Directions in Psychological Science, 18, 127-131. https://doi.org/10.1111/j.1467-8721.2009.01622.x

Chu, X., Zhou, Y., Hu, Z. et al. (2016). 24-Hour-Restraint Stress Induces Long-Term Depressive-Like Phenotypes in Mice. Scientific Reports, 6, Article No. 32935.

Dallerac, G., \& Rouach, N. (2016). Astrocytes as New Targets to Improve Cognitive Functions. Progress in Neurobiology, 144, 48-67.

Dalton, V. S., Kolshus, E., \& McLaughlin, D. M. (2014). Epigenetics and Depression: Return of the Repressed. Journal of Affective Disorders, 155, 1-12. https://doi.org/10.1016/j.jad.2013.10.028

DePitta, M., Volman, V., Berry, H., Parpura, V. et al. (2013). Computational Quest for Understanding the Role of Astrocyte Signaling in Synaptic Transmission and Plasticity. Frontiers in Computational Neuroscience, 6, 98.

Ferrari, A. J., Charlson, F. J., Norman, R. E., Patten, S. B. et al. (2010). Burden of Depressive Disorders by Country, Sex, Age, and Year. Findings from Global Burden of Disease Study. PLoS Medicine, 10, e1001547.

Freud, S. (1917). Trauer und Melancholie. In: Gesammelte Werke, Bd. II, S. Fischer, Frankfurt.

Fuxe, K., Boroto-Escuela, D. O., Ciruela, F., Guidolin, V. D., \& Agnati, L. F. (2014). Receptor-Receptor Interactions in Heteroreceptor Complexes: A New Principle in Biology. Focus on Their Role in Learning and Memory. Neuroscience Discovery, 2, 6.

Harada, K., Kamiya, T., \& Tsuboi T. (2016). Gliotransmitter Release from Astrocytes: Functional, Developmental, and Pathological Implications in the Brain. Frontiers in Neuroscience, 9, 499. https://doi.org/10.3389/fnins.2015.00499

Hasler, G. (2010). Pathophysiology of Depression: Do We Have Any Solid Evidence of Interest to Clinicians? World Psychiatry, 9, 155-161. https://doi.org/10.1002/j.2051-5545.2010.tb00298.x

Hobson, J. A., \& Scheibel, A. B. (1980). The Brainstem Core: Sensorimotor Integration and Behavioral State Control. Cambridge: MIT Press. 
Humphries, M. D., Gurney, K., \& Prescott, T. J. (2006). The Brainstem Reticular Formation Is a Small-World, Not Scale-Free, Network. Proceedings of the Royal Society B, 273, 503-511. https://doi.org/10.1098/rspb.2005.3354

Iberall, A. S., \& McCulloch, W. S. (1969). The Organization Principle of Complex Living Systems. Journal of Basic Engineering, 91, 290-294. https://doi.org/10.1115/1.3571099

Ishida, Y., Nagai, A., Kobayashi, S., \& Kim, S. U. (2006). Upregulation of Protease-Activated Receptor-1 in Astrocytes in Parkinson Disease: Astrocyte-Mediated Neuroprotection through Increased Levels of Glutathione Peroxidase. Journal of Neuropathology \& Experimental Neurology, 65, 66-77. https://doi.org/10.1097/01.jnen.0000195941.48033.eb

Josephson, J. R., \& Josephson, S. G. (Eds.) (1995). Abductive Inference: Computation, Philosophy, Technology. Cambridge: Cambridge University Press.

Kettenmann, H., \& Zorec, R. (2013). Release of Gliotransmitters and Transmitter Receptors in Astrocytes. In H. Kettenmann, \& B. R. Ransom (Eds.), Neuroglia (pp. 197-211). New York: Oxford University Press.

Kilmer, W. L., McCulloch, W. S., \& Blum, J. (1969). A Model of the Vertebrate Central Command System. International Journal of Man-Machine Studies, 1, 279-309. https://doi.org/10.1016/S0020-7373(69)80025-8

Kuss, D. J., \& Lopez-Fernandez, O. (2016). Internet Addiction and Problematic Internet Use: A Systematic Review of Clinical Research. World Journal of Psychiatry, 6, 143-176. https://doi.org/10.5498/wjp.v6.i1.143

Li, D., Agulhon, C., Schmidt, E., Oheim, M., \& Ropert, N. (2013). New Tools for Investigating Astrocyte-Neuron Communication. Frontiers in Cellular Neuroscience, 7, 193.

Mayberg, H. S., Brannan, S. K., Tekell, J. L. et al. (2000). Regional Metabolic Effects of Fluoxetine in Major Depression: Serial Changes and Relationship to Clinical Response. Biological Psychiatry, 48, 830-843. https://doi.org/10.1016/S0006-3223(00)01036-2

McCulloch, W. S. (1966). Commentary. In L. Thayer (Ed.), Communication: Theory and Research (pp. 51-58). Springfield: Thomas Publisher.

Mitterauer, B. J. (2007). Where and How Could Intentional Programs Be Generated in the Brain?: A Hypothetical Model Based on Glial-Neuronal Interactions. BioSystems, 88, 101-112. https://doi.org/10.1016/j.biosystems.2006.04.003

Mitterauer, B. J. (2009). Narziss und Echo. Ein psycho-biologisches Modell der Depression. Vienna: Springer. https://doi.org/10.1007/978-3-211-99140-4

Mitterauer, B. J. (2011). Downregulation and Upregulation of Glial Connexins May Cause Synaptic Imbalances Responsible for the Pathophysiology of Bipolar Disorder. CNS Neuroscience \& Therapeutics, 17, 281-293. https://doi.org/10.1111/j.1755-5949.2010.00178.x

Mitterauer, B. J. (2015). Model of the Reticular Formation of the Brainstem Based on Glial-Neuronal Interactions. Cognitive Computation, 7, 64-73. https://doi.org/10.1007/s12559-014-9260-5

Nie, Y., \& Sun, H. (2016). Why Do Workaholics Experience Depression? A Study with Chinese University Teachers. Journal of Health Psychology, 21, 2339-2349. https://doi.org/10.1177/1359105315576350

Oberheim, N. A., Takano, T., Han, X. et al. (2009). Uniquely Hominid Features of Adult Human Astrocytes. Journal of Neuroscience, 29, 3276-3287. https://doi.org/10.1523/JNEUROSCI.4707-08.2009

Ovidius Naso, P. (1983). Metamorphosen. München: Artennis. 
Peirce, C. S. (1958). Collected Papers. Cambridge, MA: University Press Harvard.

Perea, G., Navarrete, M., \& Arague, A. (2009). Tripartite Synapses: Astrocytes Process and Control Synaptic Information. Trends in Neurosciences, 32, 421-431. https://doi.org/10.1016/j.tins.2009.05.001

Pittenger, C., \& Duman, R. S. (2008). Stress, Depression, and Neuroplasticity: A Convergence of Mechanisms. Neuropsychopharmacology, 33, 88-109. https://doi.org/10.1038/sj.npp.1301574

Quesseveur, G., Portal, B., Basic, J. A. et al. (2015). Attenuated Levels of Hippocampal Connexin 43 and Its Phosphorylation Correlate with Antidepressant and Anxiolytic-Like Activation in Mice. Frontiers in Cellular Neuroscience, 9, 490.

Ransom, B. R., \& Giaume, C. (2013). Gap Junctions, Hemichannels. In H. Keltenmann, \& B. R. Ransom (Eds.), Neuroglia (pp. 292-305). New York: Oxford University Press.

Rial, D., Lemos, C., Pinheiro, H. et al. (2015). Depression as a Glial-Based Synaptic Dysfunction. Frontiers in Cellular Neuroscience, 9, 521. https://doi.org/10.3389/fncel.2015.00521

Scheibel, M. E., \& Scheibel, A. B. (1968). The Brainstem Core: An Integrative Matrix. In M. Mesarovic (Ed.), System Theory and Biology (pp. 261-285). New York: Springer. https://doi.org/10.1007/978-3-642-88343-9_13

Smeets, E., Roefs, A., \& Jansen, A. (2009). Experimentally Induced Chocolate Craving Leads to an Attentional Bias in Increased Distraction but Not in Speeded Detection. Appetite, 53, 370-375. https://doi.org/10.1016/j.appet.2009.07.020

Solan, J. L., \& Lampe, P. D. (2009). Connexin43 Phosphorylation: Structural Changes and Biological Effects. Biochemical Journal, 419, 261-272. https://doi.org/10.1042/BJ20082319

Stuffrein-Roberts, S., Joyce, P. R., \& Kennedy, M. A. (2008). Role of Epigenetics in Mental Disorders. Australian \& New Zealand Journal of Psychiatry, 42, 97-107. https://doi.org/10.1080/00048670701787495

Thaipisuttikul, P., Ittasakul, P., Waleprakhon, P. et al. (2014). Psychiatric Comorbiditiesin Patients with Major Depressive Disorder. Neuropsychiatric Disease and Treatment, 10, 2097-2103.

Verkhratsky, A., Rodrigues, J. J., \& Steardo, L. (2014). Astrogliopathology: A Central Element of Neuropsychiatric Diseases? The Neuroscientist, 20, 576-588. https://doi.org/10.1177/1073858413510208

Wang, Q., Jie, W., Liu, J., Yang, J., \& Gao, T. (2017). An Astroglial Basis of Major Depressive Disorder? An Overview. Glia, 65, 1227-1250. https://doi.org/10.1002/glia.23143

Yu, W., Mechavar, N., Kratic, S. et al. (2012). Upregulation of Astrocytic Alpha 7 Nicotinic Receptors in Alzheimer's Disease Brain-Possibly Relevant to Amyloid Pathology. Molecular Neurodegeneration, 7, 7. https://doi.org/10.1186/1750-1326-7-S1-O7

Zhang, T. Y., \& Meaney, M. J. (2010). Epigenetics and the Environmental Regulation of Genome and Its Function. Annual Review of Psychology, 61, 439-466. https://doi.org/10.1146/annurev.psych.60.110707.163625 